\title{
Therapeutic approach in patients with chronic venous insufficiency
}

\section{Abordarea terapeutică a pacientului cu insuficienţă venoasă cronică}

Marilena SPIRIDON, Dana CORDUNEANU

Clinica de Cardiologie, Spitalul Clinic de Urgenţă „Sf. Spiridon“, Iaşi, România

\section{REZUMAT}

Insuficiența venoasă cronică (IVC), cauză frecventă a edemelor de la nivelul membrelor inferioare, reprezintă o consecință severă a disfuncției valvelor venoase, disfuncție ce apare ca urmare a hipertensiunii venoase coroborată adesea cu procesele degenerative ce apar la acest nivel. Insuficiența venoasă cronică defineşte doar stadiile severe ale bolii venoase cronice (BVC) ce sunt însoțite de leziuni morfologice şi funcționale severe, cu alterarea semnificativă a calității vietii.

Tratamentul IVC implică, în funcție de severitatea cazului, o combinație de măsuri generale, nefarmacologice, farmacologice şi chirurgicale.

Măsurile nefarmacologice presupun utilizarea ciorapilor compresivi care, prin presiunea externă continuă şi controlată, pot îmbunătați întoarcerea venoasă, conducând la o ameliorare semnificativă a simptomatologiei.

Tratamentul farmacologic are ca scop pe de o parte ameliorarea hemodinamicii prin scăderea vâscozității sângelui, reducerea presiunii venoase şi prevenirea formării trombilor intravasculari, iar pe de altă parte refacerea glicocalixului/endoteliului vascular, reducerea inflamației parietale şi creşterea tonusului peretelui venos. Pentru această patologie, sulodexid reprezintă un produs biologic inovator cu acțiuni polifarmacologice ce țintesc mai multe situsuri implicate în patogeneza BVC/IVC şi care reuşeşte astfel să amelioreze hemodinamica şi să refacă structura vasculară, ceea ce duce la o ameliorare semnificativă a simptomatologiei şi la încetinirea semnificativă a progresiei bolii.

Tratamentul chirurgical rămâne soluția de ales atât în cazul pacienților tratați inițial conservator şi la care simptomele persistă sau se agravează, cât şi în cazul celor care ajung la medic deja într-un stadiu sever de boală.
\end{abstract}

Cuvinte cheie: boală venoasă cronică, glicocalix, insuficiență venoasă cronică, sulodexid, terapie compresivă, vasculotrop

\footnotetext{
ABSTRACT

Chronic venous insufficiency (CVI), frequent cause of lower limb edema, represents a severe consequence of the dysfunction of the venous valve, which results from the venous hypertension together with the degenerative processes at this level. CVI defines only the severe stages of the chronic venous disease (CVD), accompanied by morphological and functional damage, with significant alteration in quality of life.

The treatment of CVI involves, depending on the severity of the case, a combination of general nonpharmacologic, pharmacologic, and surgical measures.

Non-pharmacologic measures involve the use of a continuous and controlled external pressure represented by compression stockings which can significantly improve the venous return and lead to a major symptoms improvement.

Pharmacologic treatment aims on one hand to alleviate hemodinamics by lowering blood viscosity, decreasing venous pressure and preventing intravascular thrombus formation and, on the other hand, restoring the
} 
vascular glycocalyx/endothelium, reducing parietal inflammation and increasing the venous wall tone. Within this pathology, sulodexide represents an innovative biological product with polypharmacological actions targeting more sites involved in the pathogenesis of CVD/CVI that alleviate hemodynamics and restore vascular structure which lead to a significant symptoms improvement and a slow disease progression.

Surgery remains the procedure of choice in patients initially treated conservatively in whom symptoms persist or worsen, but also in case of those who already come to doctor in a severe stage of the disease.

Keywords: chronic venous disease, chronic venous insufficiency, compressive therapy, glycocalix, sulodexide, vasculotrop agent

\section{INTRODUCERE}

Insuficienţa venoasă cronică (IVC), cauză frecventă a edemelor de la nivelul membrelor inferioare, reprezintă o consecinţă severă a disfuncţiei valvelor venoase, disfuncţie ce apare ca urmare a hipertensiunii venoase coroborată adesea și cu procesele degenerative ce apar la acest nivel odată cu înaintarea în vârstă. Cauzele ce duc la hipertensiune venoasă pot fi de natură traumatică, obstructivă (ex. tromboză venoasă profundă) și posturală (ex. ortostatism prelungit) sau pot ţine de prezenţa unor antecedente sau comorbidităţi favorizante (ex. tratamente cronice cu progesteron, hipertensiune pulmonară, tumori compresive pelvine etc). Expresia clinică cel mai frecvent întalnită a hipertensiunii venoase însoţită de compromiterea sistemului valvular este reprezentată de dilataţiile pereţilor venelor din teritoriul venos superficial (varicozităţi) (1). Edemul apare când hipertensiunea venoasă ajunge să se manifeste la nivel capilar, unde alterează progresiv schimburile hemato-tisulare.

Boala venoasă cronică (BVC) este entitatea patologică ce cuprinde toate modificările morfologice și funcţionale exprimate clinic prin semne și simptome ale sistemului venos de la nivelul membrelor inferioare, în timp ce insuficienţa venoasă cronică (IVC) definește doar stadiile severe ale BVC, însoţite de leziuni morfologice și funcţionale severe, cu alterarea semnificativă, a calităţii vieţii (2-4).

\section{CLASIFICAREA CLINICĂ A BVC (DIAGNOSTIC „C“)}

CO - fără semne vizibile sau palpabile ale bolii venoase

$\mathrm{C} 1$ - telangiectazii, vene reticulate

$\mathrm{C} 2$ - varice (diametru $\geq 3 \mathrm{~mm}$ )

C3 - edem, fără modificări ale pielii

C4 - modificări ale pielii atribuite bolii venoase (ex: pigmentare, eczeme venoase, lipodermatoscleroză)
C5 - modificări ale pielii, așa cum sunt definite mai sus, cu ulceraţii închise (epitelizate/ vindicate)

C6 - modificări ale pielii, așa cum sunt definite mai sus, cu ulceraţii active.

\section{FIZIOPATOLOGIE}

Hipertensiunea venoasă conduce la incompetenţă valvulară, ceea ce permite refluxul sângelui în porţiunea subiacentă, propagând astfel centrifug hipertensiunea venoasă. Acţiunea cronică a hipertensiunii venoase ajunge în final la nivelul capilarelor din ţesuturile membrelor inferioare, unde produce anomalii ce ţin de permeabilitatea acestor vase cu perete extrem de subţire. Ca urmare, lichidul, proteinele și elementele figurate sanguine ajung să pătrundă în ţesuturi. Leziunile parietale produse de hipertensiunea venoasă determină inflamaţie la nivelul peretelui venos, modificări în structura microvasculară și slaba oxigenare a ţesuturilor și a pielii, ceea ce conduce în final la tulburările de troficitate caracteristice (5). Iniţial s-a crezut că incompetenţa valvulară venoasă reprezintă modificarea primară din insuficienţa venoasă cronică. Dovezile actuale pledează pentru fragilitatea peretelui venos în condiţii de presiune ridicată, ceea ce produce dilatare și, secundar, incompetenţă valvulară (6). Aceste disfuncţii anatomice și funcţionale ajung să producă în timp modificări la nivelul pielii și a ţesutului celular subiacent, precum edem, hiperpigmentare, lipodermatoscleroză, atrofie albă și eczeme, determinând în final o fragilitate crescută a pielii, cu creșterea riscului apariţiei ulceraţiilor și vindecare dificilă (5).

\section{FACTORI DE RISC PENTRU BVC/IVC}

- istoricul familial;

- vârsta peste 30 de ani;

- tromb(i) la nivelul venelor superficiale sau profunde; 
- sexul feminin;

- ortostatismul prelungit;

- sarcinile multiple;

- sedentarismul;

- hipertensiunea arterială;

- obezitatea (1).

\section{DIAGNOSTIC}

- Examenul clinic reprezintă primul pas diagnostic în IVC.

- Examenul Doppler vascular permite examinatorului să evidenţieze și să asculte fluxul sanguin. Cea mai mare fidelitate este oferită de examinarea ecografică duplex, care oferă o imagine clară a venei, putând astfel fi obiectivate atât obstacolele reprezentate de trombi, precum și disfuncţiile valvulare.
- Pentru a exclude alte etiologii, pot fi utilizate examene complementare, precum CT sau RMN (1).

\section{TRATAMENT}

Tratamentul IVC implică, în funcţie de severitatea cazului, o combinaţie de măsuri generale, nefarmacologice, farmacologice și chirurgicale (Fig. 1).

\section{Măsurile generale cuprind:}

- adaptarea dietei și a stilului de viaţă pentru eliminarea circumstanţelor de apariţie a bolii;

- evitarea ortostatismului prelungit sau a șederii prelungite pe scaun;

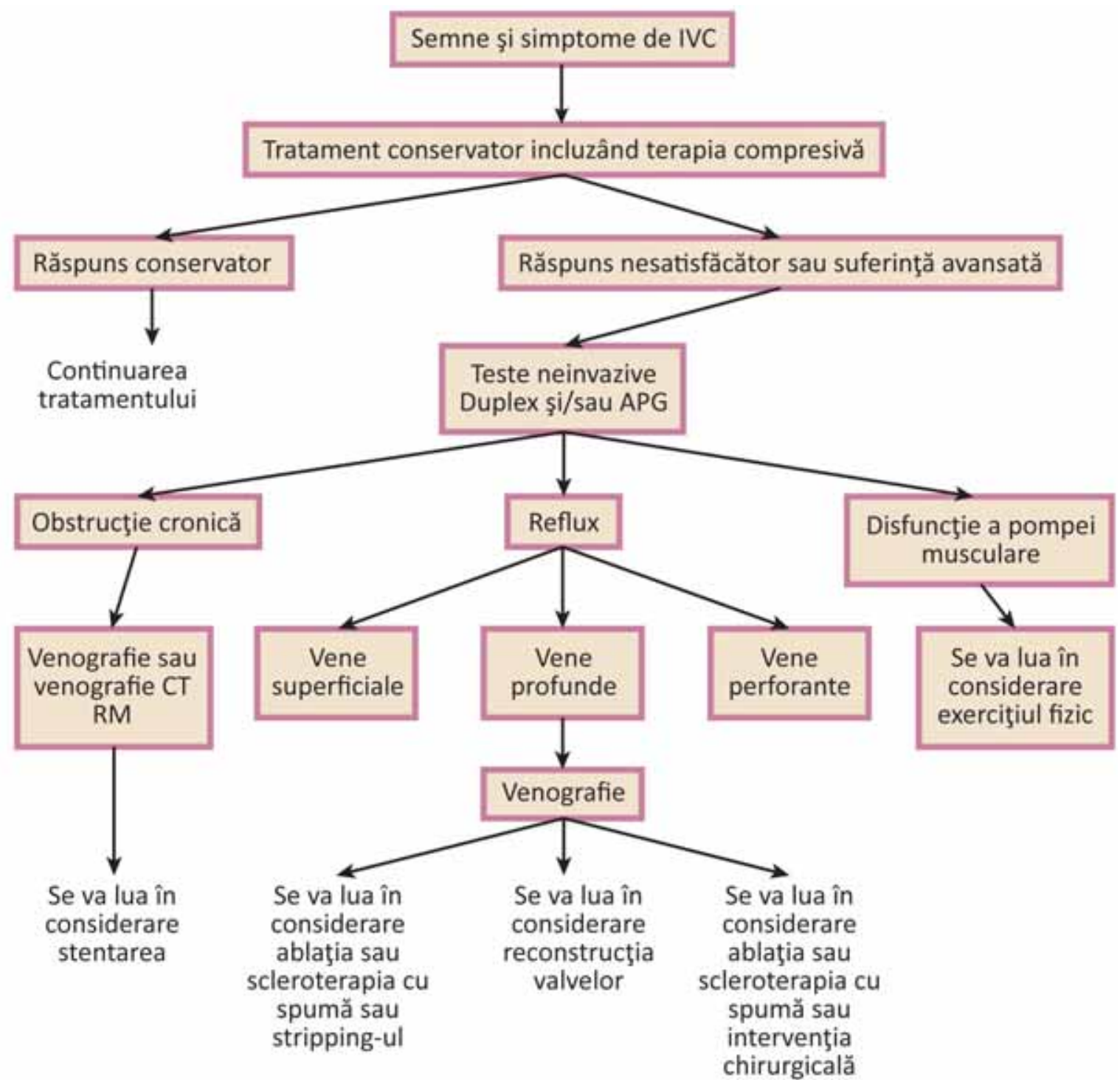

FIGURA 1. Algoritm de tratament chirugical în BVC/IVC 
- efectuarea regulată de exerciţii fizice, precum mersul, ce pot îmbunătăţi funcţia pompei musculare a gambei (1).

\section{Măsurile nefarmacologice presupun:}

- utilizarea ciorapilor compresivi care, prin presiunea externă continuă și controlată, pot ameliora întoarcerea venoasă, conducând la o ameliorare semnificativă a simptomatologiei.

Sistemele de compresie aplicate extern la nivelul gambei cresc presiunea creată natural de piele și ţesuturile subiacente și contracarează forţa gravitaţională. Pot ameliora simptomatologia din IVC prin acţiunea la nivelul sistemului venos și limfatic, ajutând la eliminarea fluidelor (sânge și limfă) stocate în membru (5).

Terapia compresivă are două mecanisme de acţiune: unul static (sau presiunea restantă) și unul dinamic, datorat modificărilor circumferinţei membrului în timpul mersului. Aplicând presiune externă, crește presiunea în membru, aceasta fiind distribuită uniform, conform legii lui Pascal. Cu cât presiunea aplicată este mai importantă, cu atât forţa de îndepărtare a fluidului crește (5).

Bandajele cu un index de rigiditate static ridicat (IRS) - inelastice - rămân rigide datorită lipsei elasticităţii. Acest lucru permite generarea intermitentă a presiunilor ridicate în timpul efortului și a presiunilor joase în timpul repausului, îmbunătăţind confortul și eficacitatea pompei musculare a gambei (5). Bandajele cu IRS scăzut asigură presiune constantă, menţinând un nivel terapeutic de compresie în timpul repausului, dar cu modificări nesemnificative în timpul efortului (5).

\begin{tabular}{|l|l|}
\hline Categorie & Presiune \\
\hline Uşoară & $<20 \mathrm{~mm} \mathrm{Hg}$ \\
\hline Medie & $\geq 20-40 \mathrm{~mm} \mathrm{Hg}$ \\
\hline Puternică & $\geq 40-60 \mathrm{~mm} \mathrm{Hg}$ \\
\hline Foarte puternică & $>60 \mathrm{~mm} \mathrm{Hg}$ \\
\hline
\end{tabular}

Ciorapii compresivi sunt necesari pentru toţi pacienţii cu BVC/IVC și în cazul persoanelor la risc, pe durata călătoriilor pe distanţe lungi, cu avionul sau autocarul. În cazurile severe (ulcere, status postchirurgical) compresia elastică externă este asigurată cu ajutorul bandajelor compresive. Toţi pacienţii la care s-a recomandat compresie elastică externă trebuie evaluaţi periodic (în medie, la fiecare 6 luni) (7).

\section{Tratamentul farmacologic - are ca scop:}

- scăderea vâscozităţii sângelui

- creșterea tonusului peretelui venos

- refacerea glicocalixului/endoteliului vascular

- reducerea inflamaţiei din peretele venos

- liza/limitarea creșterii/prevenirea formării trombusului

Măsurile farmacologice constau în administrarea de flebotonice (flavonoide, saponine, calciu dobesilat etc.) și antitrombotice-vasculotrope (sulodexid).

Sulodexid este un produs biologic cu acţiuni polifarmacologice care ţintesc mai multe situsuri implicate în patogeneza BVC/IVC ce ţin atât de conţinător (capitalul venos), cât și de conţinut (coloana de sânge) (8). Sulodexid este un antitrombotic, cu proprietăţi fibrinolitice și hipolipemiante și, în același timp, un vasculotrop, cu potenţial de refacere a glicocalixului, endoteliului și a structurilor fibrilare subendoteliale. Ca urmare a acestor acţiuni particulare, sulodexid reușește să amelioreze hemodinamica și să refacă structura vasculară, ceea ce duce la ameliorarea simptomatologiei, și încetinirea semnificativă a progresiei bolii.

Efectele farmacologice ale sulodexid diferă substanţial de cele ale altor glicozaminoglicani cu proprietăţi anticoagulante, prin timpul de înjumătăţire mai mare, efectele profibrinolitice si hipolipemiante adăugate, dar mai ales prin riscul mic de sângerare. Acţiunea duală inhibitorie a trombinei, atât via antitrombină, cât și prin intermediul cofactorului II, conferă sulodexid un puternic efect antitrombotic și, totodată, un risc redus de sângerare (8).

Eficacitatea sulodexid (produs de compania farmaceutică Alfa Wassermann sub denumirea de Vessel Due ${ }^{\circ} \mathrm{F}$ ) a fost demonstrată în mai multe studii clinice la pacienţii cu boală venoasă cronică, boală arterială periferică, coronaropatii, accidente ischemice vasculare cerebrale, infarct miocardic, sindrom post-trombotic, complicaţii vasculare în cadrul diabetului (8). Aceste dovezi au făcut ca sulodexid să fie inclus în ghidurile terapeutice actuale, care îl recomandă drept una dintre cele mai eficiente, sigure și documentate terapii în afecţiunile vasculare cu risc de tromboză.

Ghidul Naţional de BVC 2016 recomandă utilizarea sulodexid ca terapie sistemică în BVC/ IVC, posologia fiind adaptată în funcţie de severitatea bolii:

- C0-C1: 1 capsulă a 250 ULS x 2/zi, între mese, cronic; 
- C3-C4: 2 capsule a 250 ULS x 2/zi, între mese, până la dispariţia clinică a edemului/tulburărilor de troficitate cutanată, apoi 1 capsulă x 2/zi, între mese, cronic;

- C5-C6: 1 fiolă a 600 ULS/zi (i.m/i.v), timp de 20-30 zile, apoi 4 capsule/zi ( 2 capsule a 250 ULS x 2/zi) până la vindecarea ulcerului (C6), după care 2 capsule/zi (1 capsulă a 250 ULS x 2/zi), între mese, cronic (9).

Ghidul American SVS/AVF, publicat in 2011, recomandă și el utilizarea sulodexidului în BVC împreună cu terapia standard (toaletare și compresie), această asociere asigurând cea mai rapidă vindecare (2-3 luni) a ulcerului venos (C6) (10).

Recent au fost publicate în "Circulation" rezultatele studiului SURVET, care arată că administrarea de sulodexid în doză de 4 capsule/zi, timp de 2 ani, la pacienţii cu istoric de tromboză venoasă profundă, trataţi iniţial timp de 3-12 luni cu anticoagulante orale, reduce la jumătate riscul de recurenţă al trombozei, în condiţii de maximă siguranţă terapeutică privind riscul de sângerare (11). La respectivii pacienţi, odată cu riscul de recurenţă se reduce și riscul de sindrom post-trombotic, una din posibilele cauze de BVC/IVC.

Studiile clinice privind interacţiunile medicamentoase ale sulodexid au demonstrat că administrarea sa pe cale orală în patologiile cardiovasculare, metabolice și în prevenţia și tratamentul trombozei nu interferează cu acţiunile farmacologice ale altor agenţi utilizaţi în aceste afecţiuni.

\section{Tratamentul chirurgical}

Tratamentul chirurgical rămâne soluţia de ales atât în cazul pacienţilor trataţi iniţial conservator, la care simptomele persistă sau se agravează, cât și în cazul celor care ajung la medic deja într-un stadiu sever de boală. El include în principal: ligatura simplă, ligatura cu stripping, scleroterapia, ablaţia cu radiofrecvenţă, terapia laser endovenoasă. Metoda aleasă de chirurgul vascular/flebolog se individualizează în funç̧ie de particularitatea și severitatea cazului. Tratamentul chirurgical nu exclude celelalte măsuri terapeutice, nici preoperator și nici postoperator.

\section{CONCLUZII}

BVC/IVC este o patologie potenţial severă, ignorată terapeutic mult timp, care solicită răbdare și complianţă din partea pacientului și atenţie din partea medicului. Este importantă alegerea optimă a tratamentului care trebuie să fie adecvat stadiului și simptomatologiei bolii, pentru a preveni eficient complicaţiile acesteia.

\section{Surse de finanțare}

Prezentul articol a fost realizat fără suportul financiar al unei terţe părţi.

\section{Conflict de interese}

Autorii declară lipsa oricărui conflict de interese care ar fi putut sta la baza realizării prezentei lucrări.

\section{BIBLIOGRAFIE}

1. What is Chronic Venous Insufficiency (CVI)? Vascular Disease Foundation 2012 (http:// vasculardisease.org/flyers/chronic-venousinsufficiency-flyer.pdf)

2. Eklop B., Rutherford R.B., Bergan J.J. et al. Revision of the CEAP classification for chronic venous disorders: Consensus Statement. J Vasc Surg 2004 Dec; 40(6): 1248-1252;

3. Eklop B., Perrin M., Delis K.T. et al. Updated terminology of chronic venous disorders: the VEIN-TERM transatlantic interdisciplinary consensus document. J. Vasc. Surg 2009 Feb; 49(2):498-501;

4. http://circ.ahajournals.org/ content/130/4/333;
5. Principles of compression in venous disease: a practitioner's guide to treatment and prevention of venous leg ulcers. Wounds International 2013;

6. Perrin M., Ramelet A.A. Pharmacological Treatment of Primary Chronic Venous Disease: Rationale, Results and Unanswered Question. Eur J Vasc Endovasc Surg 2011 Jan; 41(1):117-125;

7. Heller J. Treatment of Chronic Venous Insufficiency. Supplement to Endovascular Today 2011 Oct; 12-15;

8. Hoppensteadt D.A., Fareed J. Pharmacological profile of sulodexide. Int Angiol 2014 Jun; 33(3):229-235;
9. Dermatovenerologie. Revista Societății Române de Dermatologie 2015; 60(3): 187-195;

10. Nelson E.A. Venous Leg Ulcers. BMJ Clin Evid. 2011; 2011: 1902;

11. Andreozzi G.M. et al. Sulodexide for the Prevention of Recurrent Venous Thromboembolism. The Sulodexide in Secondary Prevention of Recurrent Deep Vein Thrombosis (SURVET) Study: A Multicenter, Randomized, Double-Blind, Placebo-Controlled Trial. Circulation 2015 Nov 17; 132(20): 1891-1897. 